\title{
TRACE ELEMENT DETERMINATION IN SUSPENDED MATTER AND IN SEDIMETNS. BY INSTRUMENTAL NEUTRON ACTIVATION ANALYSIS
}

\author{
W. CALMANO, K. H. LIESER \\ Fachbereich Anonganische Chemie und Kernchemie der Technischen Hochschule Darmstadt, \\ $D$ - 6100 Darmstadt (FRG)
}

(Received December 3, 1980)

\begin{abstract}
By means of instrumental neutron activation, more than 20 trace elements are determined in suspended matter in Rhine water, Main water and Rhine sediments. Monoelement and multielement standards are used for calibration. Sample collection, separation of suspended matter by filtration or centrifugating and sample preparation are described. The results obtained by filtration and by centrifuging are compared. Interferences in evaluation of the $\gamma$-spectra and their influence on the results are discussed. Systematic errors are detected by participation in ring analysis.
\end{abstract}

\section{Introduction}

There is a growing interest in quantitative determination of toxic substances in the environment. Besides the great number of organic compounds, many heavy metals play an important role because of their toxic effect. They are often present in very small concentrations in water, suspended matter and sediments.

For their determination instrumental neutron activation has the following advantages. It allows the simultaneous determination of a great number of trace elements (multielement method), it is very sensitive and gives reliable results in the range of very low concentrations because it is not easily affected by interferences if the samples are properly prepared.

In a previous publication we reported on the application of neutron activation as a routine method for determination of trace elements in water. ${ }^{1}$ In this work the determination of trace elements in suspended matter and in sediments is described.

\section{Sample collection}

\section{Experimental and results}

The water samples were collected in February 1976 and January 1977 from the middle of the Rhine River near Gernsheim in such a manner that the water did not come into contact with metals. Only plastics or plastic-coated materials were used. Dependent on the content of suspended matter in the river, sample volumes 
up to 2001 were taken. Before use the containers were treated with nitric acid (suprapur), washed with tridestilled water several times and finally rinsed with the water to be collected thoroughly. The samples were further processed immediately after collection whenever possible.

\section{Separation of suspended matter}

Three different methods are applicable for the separation of suspended matter from water samples:

Sedimentation. This method depends on the density and the size of the particles. If, for instance, a sedimentation vessel of $1 \mathrm{~m}$ height is used, it takes about 10 days until particles $>1 \mu \mathrm{m}$ are deposited. ${ }^{2}$ During this time chemical changes may take place and biological processes cannot be neglected. Therefore, this method cannot be recommended.

Filtration. Usually membrane filters with $0.45 \mu \mathrm{m}$ pore size are used. Particles with a grain size below $0.45 \mu \mathrm{m}$ are not retained and, therefore are considered to be constituents of the solution. The water volume which can be filtered within a reasonable time is restricted to $100-300 \mathrm{ml}$ under normal conditions. By use of pressure filtration, volumes can be put through which are about one order of magnitude greater.

Centrifuging. This method, like sedimentation, depends on the density and the size of the particles. If a flow centrifuge is available, greater amounts of suspended matter can be separated. By variation of the speed and the flow rate, the particle size of the separated particles can be varied.

In this work filtration and centrifuging were used. The plastic apparatus for filtration consisted of an upper part and a lower part which were locked magnetically. Thereby the filter could be changed easily and without risk of contamination. Membrane filters "Nuclepore" with $0.4 \mu \mathrm{m}$ pore size were used. The polycarbonate filters proved to have a lower trace element content then other products, which may also be due to their small thickness.

During filtration the filters are blocked up relatively soon. Thereby the effective pore size becomes also smaller and particles with grain size $<0.4 \mu \mathrm{m}$ are retained to an increasing extent. Although this effect may be favourable, the rate of filtration decreases so much that only small amounts of suspended matter can be separated by this method. In this respect it is a great advantage of neutron activation that the small amounts of material obtained are sufficient for trace element determination.

For centrifuging of the water samples, a flow centrifuge (Junior 15000 from Heraeus Christ) was used. The maximum speed was $10000 \mathrm{rpm}$, the maximum flow rate $1.2 \mathrm{l} / \mathrm{min}$. Depending on the content of suspended matter, 1 to $10 \mathrm{~g}$ 
material could be isolated from 1001 water. The grain size of the suspended matter separated was calculated to be of the same order of magnitude as in the case of filtration.

The trace element content found in Rhine water for suspended matter and the solution after centrifuging and filtration by instrumental neutron activation analysis are presented in Table 1 . In general the trace element content in filtered samples of suspended matter is somewhat higher. This may be due to the adsorption of trace elements during filtration.

Furthermore the separation principle is different for centrifuging and filtration, as mentioned above. Whereas the grain size is the only selecting factor in the case of filtration, the density of the particles plays also an important role in the case of centrifuging.

Table 1

Trace element content in Rhine water

\begin{tabular}{|c|c|c|c|c|}
\hline \multirow[b]{2}{*}{ Element } & \multicolumn{2}{|c|}{ Suspended matter, ppm } & \multicolumn{2}{|c|}{ Solution, ppb } \\
\hline & $\begin{array}{c}\text { Separation } \\
\text { by centrifuging }\end{array}$ & $\begin{array}{c}\text { Separation } \\
\text { by filtration }\end{array}$ & $\begin{array}{c}\text { Separation } \\
\text { by centrifuging }\end{array}$ & $\begin{array}{c}\text { Separation } \\
\text { by filtration }\end{array}$ \\
\hline Ag & 6.73 & 7.59 & 0.014 & 0.030 \\
\hline As & 14.0 & 12.0 & 0.70 & 0.38 \\
\hline $\mathrm{Au}$ & 0.20 & 0.33 & 0.007 & 0.004 \\
\hline $\mathrm{Ba}$ & 478 & 473 & 38.6 & 41.7 \\
\hline $\mathrm{Br}$ & 19.0 & 24.4 & 116.5 & 103 \\
\hline $\mathrm{Ca}$ & 63104 & 81487 & 61030 & 52350 \\
\hline $\mathrm{Ce}$ & 53.5 & 55.0 & 0.33 & 0.15 \\
\hline Co & 13.9 & 14.8 & 0.36 & 0.20 \\
\hline $\mathrm{Cr}$ & 209 & 282 & 1.94 & 0.82 \\
\hline Cs & 21.5 & 24.1 & 0.30 & 0.10 \\
\hline $\mathbf{E u}$ & 1.15 & 1.23 & 0.0012 & 0.0006 \\
\hline $\mathrm{Fe}$ & 31366 & 35029 & 295 & 15.6 \\
\hline $\mathrm{Hg}$ & 0.53 & 1.00 & 1.36 & 0.41 \\
\hline $\mathrm{K}$ & 20279 & 22772 & n.d. & n.d. \\
\hline $\mathrm{La}$ & 31.1 & 31.2 & 0.26 & 0.10 \\
\hline $\mathrm{Na}$ & 2812 & 2712 & 46158 & 40750 \\
\hline $\mathbf{R b}$ & 129 & 132 & 4.63 & 3.40 \\
\hline Sb & 2.55 & 2.93 & 0.36 & 0.27 \\
\hline Sc & 10.7 & 11.1 & 0.09 & 0.006 \\
\hline $\mathrm{Se}$ & 1.80 & 2.16 & 0.19 & 0.11 \\
\hline $\mathrm{Ta}$ & 0.79 & 0.76 & 0.0011 & n.d. \\
\hline $\mathrm{U}$ & 3.36 & 3.87 & 0.80 & 0.62 \\
\hline $\mathrm{Zn}_{\mathbf{n}}$ & 605 & 688 & 12.0 & 5.29 \\
\hline
\end{tabular}

n.d. $=$ not determined. 


\section{W. CALMANO, K. H. LIESER: TRACE ELEMENT DETERMINATION}

The relatively high values found for chromium and iron in solution after centrifuging can be explained by the fact that the rotor in the centrifuge is made of stainless steel, which may give off small amounts of chromium and iron into the solution during operation.

\section{Preparation of the samples, irradiation and measurements}

The filtered samples of suspended matter were dried at $50{ }^{\circ} \mathrm{C}$ in a dust-shielded box until constant weight was obtained. The suspended matter which was centrifuged and adhered in form of a sludge with relatively high water content to the wall of the rotor was freeze-dried.

For neutron activation, about $100 \mathrm{mg}$ of the material was filled in a quartz ampoule ("Suprasil") which was sealed by melting. The filtered samples were transferred into the ampoules together with the filter. Before use, the ampoules were treated with nitric acid (suprapur), washed with tridestilled water several times and dried at $200^{\circ} \mathrm{C}$. The amounts of trace elements found in "Nuclepore" filters and quartz ampoules and the amounts found in suspended matter from $200 \mathrm{ml}$ Rhine water are listed in Table 2. It can be seen from this table that the values for the blank ("Nuclepore" filter plus "Suprasil" quartz ampoule) are generally at least two orders of magnitude lower than the trace element content in the samples and can therefore be neglected.

Table 2

Content of trace elements in one "Nuclepore" filter plus one "Suprasil" quartz ampoule and in $29.8 \mathrm{mg}$ suspended matter obtained by filtration from $200 \mathrm{ml}$ Rhine water

\begin{tabular}{l|c|c}
\hline Element & $\begin{array}{c}\text { In "Nuclepore"-filter } \\
\text { plus "Suprasil" quartz } \\
\text { ampoule, }\end{array}$ & $\begin{array}{c}\text { In } 29.8 \text { mg suspended } \\
\text { matter, } 8\end{array}$ \\
\hline $\mathrm{Au}$ & $1.03 \cdot 10^{-10}$ & $2.70 \cdot 10^{-8}$ \\
$\mathrm{Ba}$ & $3.80 \cdot 10^{-8}$ & $1.50 \cdot 10^{-5}$ \\
$\mathrm{Br}$ & $1.50 \cdot 10^{-8}$ & $7.00 \cdot 10^{-7}$ \\
$\mathrm{Ce}$ & $7.70 \cdot 10^{-10}$ & $2.30 \cdot 10^{-5}$ \\
$\mathrm{Co}$ & $1.50 \cdot 10^{-9}$ & $4.00 \cdot 10^{-7}$ \\
$\mathrm{Cr}$ & $2.60 \cdot 10^{-8}$ & $8.00 \cdot 10^{-6}$ \\
$\mathrm{Fe}$ & $2.50 \cdot 10^{-7}$ & $9.60 \cdot 10^{-4}$ \\
$\mathrm{Hg}$ & $1.60 \cdot 10^{-9}$ & $3.00 \cdot 10^{-8}$ \\
$\mathrm{Na}$ & $7.30 \cdot 10^{-7}$ & $8.50 \cdot 10^{-5}$ \\
$\mathrm{Sb}$ & $3.50 \cdot 10^{-10}$ & $7.90 \cdot 10^{-8}$ \\
$\mathrm{Sc}$ & $3.35 \cdot 10^{-11}$ & $3.10 \cdot 10^{-7}$ \\
$\mathrm{Zn}$ & $1.75 \cdot 10^{-8}$ & $1.40 \cdot 10^{-5}$
\end{tabular}


The samples were irradiated together with an iron standard $(\approx 3 \mathrm{mg})$ for 24 hours at a neutron flux of $9 \cdot 10^{13} \mathrm{~cm}^{-2} \cdot \mathrm{s}^{-1}$ in the research reactor FR2 at the nuclear centre Karlsruhe. A multielement standard was also used. This multielement standard was the sample of a Rhine sediment with known trace element content. The sample was taken near Koblenz April 7, 1976, by the "Bundesanstalt fur Gewässerkunde". After freeze-drying, it was ground in a porcelain mortar and sieved. The fraction $>630 \mu \mathrm{m}$ ( $5 \%$ of the dry mass) was discarded. The rest was sieved again and the fraction $<200 \mu \mathrm{m}$ (93\% of the dry mass) was used. This sample was dried for 2 hours at $105^{\circ} \mathrm{C}$, which caused a weight loss of $2 \%$ (moisture). The

Table 3

Comparison of trace element determination in a $\mathbf{R}$ hine sediment by instrumental neutron activation with the results of a ring analysis

\begin{tabular}{|c|c|c|c|c|c|}
\hline \multirow[b]{2}{*}{ Element } & \multicolumn{2}{|c|}{$\begin{array}{c}\text { Instrumental neutron } \\
\text { activation analysis }\end{array}$} & \multicolumn{2}{|c|}{ Ring analysis } & \multirow{2}{*}{$\begin{array}{l}\text { Deviation of the value } \\
\text { obtained by neutron } \\
\text { activation analysis from } \\
\text { the mean of the ring } \\
\text { analysis, } \%\end{array}$} \\
\hline & $\begin{array}{c}\text { Mean of } 4 \\
\text { independent } \\
\text { determinations, } \\
\text { ppm }\end{array}$ & $\begin{array}{l}\text { Relative error } \\
\text { of the mean } \\
\text { value }(2 \sigma) \text {, } \\
\% \sigma\end{array}$ & $\begin{array}{c}\text { Mean of } 19 \\
\text { determinations, } \\
\text { ppm }\end{array}$ & $\begin{array}{l}\text { Relative error } \\
\text { of the mean } \\
\text { value }(2 \sigma) \\
\%\end{array}$ & \\
\hline $\mathbf{A g}$ & 10.5 & 0.8 & 9.3 & 17 & +13 \\
\hline As & 16.8 & 5.4 & 20.7 & 12 & -19 \\
\hline $\mathrm{Au}$ & C.16 & 44 & 0.15 & 12 & +6 \\
\hline $\mathrm{Ba}$ & 703 & 6.7 & 966 & 12 & -27 \\
\hline $\mathrm{Br}$ & 35.5 & 6.5 & 32.7 & 13 & +9 \\
\hline $\mathrm{Ca}$ & 52507 & 3.3 & 59503 & 15 & -12 \\
\hline $\mathrm{Ce}$ & 49.3 & 2.2 & 55.4 & 19 & -11 \\
\hline Co & 19.8 & 4.5 & 21.9 & 9 & -10 \\
\hline $\mathrm{Cr}$ & 413 & 2.9 & 450 & 6 & -8 \\
\hline $\mathrm{Cs}$ & 15.5 & 4.5 & 15.6 & 11 & -0.6 \\
\hline E.u & 1.0 & 0.0 & 0.96 & 19 & +4 \\
\hline $\mathrm{Fe}$ & 30472 & 3.6 & 28900 & 6 & +5 \\
\hline Hf & 5.5 & 5.6 & 4.9 & 13 & +12 \\
\hline $\mathrm{Hg}$ & 4.8 & 6.3 & 4.4 & 8 & +9 \\
\hline $\mathbf{K}$ & 20720 & 14.4 & 18646 & 20 & +11 \\
\hline $\mathrm{La}$ & 31.7 & 3.8 & 30.7 & 11 & +3 \\
\hline $\mathrm{Na}$ & 3607 & 6.5 & 3780 & 13 & -5 \\
\hline $\mathbf{R b}$ & 175 & 5.4 & 119 & 6 & +47 \\
\hline $\mathrm{Sb}$ & 3.9 & 5.1 & 5.4 & 15 & -28 \\
\hline Sc & 9.4 & 3.2 & 10.5 & 25 & -10 \\
\hline $\mathrm{Se}$ & 4.5 & 22.2 & 2.0 & 21 & +125 \\
\hline $\mathbf{U}$ & 7.5 & 8.0 & 5.1 & 28 & +47 \\
\hline $\mathrm{Zn}$ & 1131 & 5.5 & 950 & 4.4 & +19 \\
\hline
\end{tabular}


trace element content was determined in a ring analysis by various methods. The results of this ring analysis are given in Table 3 . The mean value of the trace element content was obtained from 19 individual values. ${ }^{3}$

The $\boldsymbol{\gamma}$-spectra were taken by use of a Ge-Li-detector. Each sample was measured 4 times. It proved to be favourable to measure the spectra of the samples 100 , 150,250 and 700 hours after the end of irradiation. In some cases a spectrum was measured again after 2000 hours in order to determine longer-lived radionuclides like ${ }^{152} \mathrm{Eu}$ and ${ }^{203} \mathrm{Hg}$, the $\gamma$-lines of which are overlapped by the $\gamma$-lines of shorter-lived radionuclides. In this way all $\gamma$-lines could, in general, be determined unequivocally.

\section{Discussion}

In instrumental neutron activation analysis of suspended matter and sediments, systematic errors by contamination and losses are relatively low. The error in weighing the samples is also low. Individual elements like $\mathrm{Hg}$ or As may partially be lost by evaporation if not enough care is taken in drying the samples or in sealing the quartz ampoules.

The accuracy of the analysis. is mainly influenced by the measurement and the evaluation of the spectra. The possible effects on the spectra can be divided into two groups: high background from those radionuclides which are relatively abundant and overlap the $\gamma$-lines. During the first two-weeks after irradiation, the high background is caused mainly by ${ }^{24} \mathrm{Na},{ }^{82} \mathrm{Br}$ and ${ }^{140} \mathrm{La}$. After decay of these radionuclides there still remains the relatively high background of longer-lived radionuclides like ${ }^{46} \mathrm{Sc}^{4}$ High background may influence the reproducibility of the results. Overlap of the $\gamma$-lines, on the other hand, may cause systematic errors.

In water analysis overlap of $\gamma$-lines needs special consideration in the following cases:

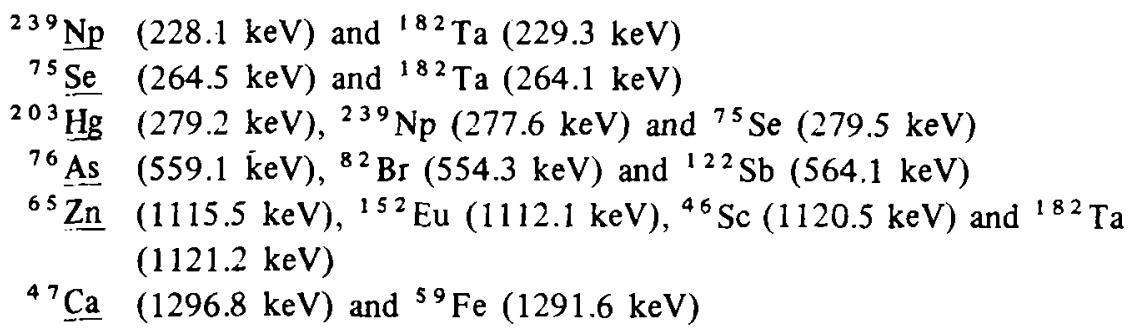

The underlined radionuclides had to be measured by evaluation of the $\gamma$-lines indicated. Other cases of overlapping in the spectra were of minor importance because other $\gamma$-lines of the radionuclides could be measured. 


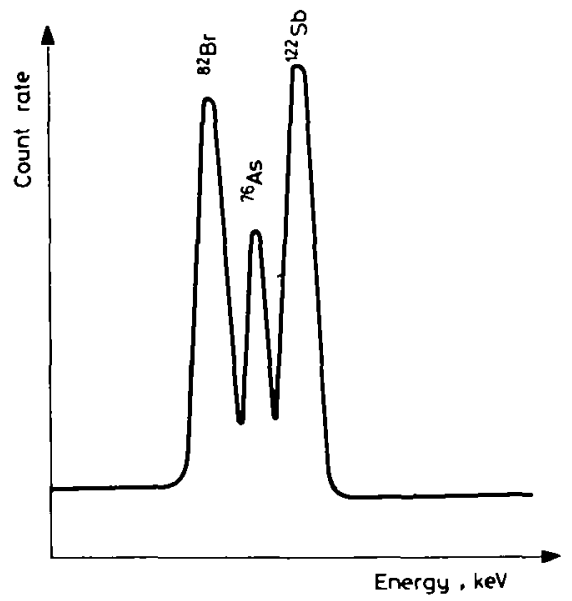

Fig. 1. Overlapping $\gamma$-lines of ${ }^{76} \mathrm{As}(559.1 \mathrm{keV}) .{ }^{82} \mathrm{Br}(554.3 \mathrm{keV})$ and ${ }^{122} \mathrm{Sb}(564.1 \mathrm{keV})$

The overlapping $\gamma$-lines of ${ }^{76} \mathrm{As},{ }^{82} \mathrm{Br}$ and ${ }^{122} \mathrm{Sb}$ (Fig. 1) can be evaluated properly if the resolution of the $\mathrm{Ge} / \mathrm{Li}$-detector is high enough $(<2 \mathrm{keV}$ at $1322 \mathrm{keV}$ ). If, however, the resolution of the detector is lower, then, in general, values for As are found which are too low. This error can be corrected by an empirical factor.

In the case of the overlapping lines of ${ }^{47} \mathrm{Ca}$ and ${ }^{59} \mathrm{Fe}$ for suspended matter the $\gamma$-line of ${ }^{59} \mathrm{Fe}$ is high compared with the $\gamma$-line of ${ }^{4} \mathrm{Ca}$ (Fig. 2). The ratio becomes more favourable with increasing decay time. High resolution of the detector is also of great importance.

The case of the overlapping lines of ${ }^{65} \mathrm{Zn},{ }^{152} \mathrm{Eu},{ }^{46} \mathrm{Sc}$ and ${ }^{182} \mathrm{Ta}$ is rather complicated (Fig. 3). Zn can only be determined by evaluation of this line of ${ }^{65} \mathrm{Zn}$ at $1115.2 \mathrm{keV}$. The neighbouring line of ${ }^{46} \mathrm{Sc}$ at $1120.5 \mathrm{keV}$ is, in general, very strong. Additionally, both lines are influenced by the lines of ${ }^{152} \mathrm{Eu}$ and ${ }^{182} \mathrm{Ta}$. Evaluation of the ${ }^{65} \mathrm{Zn}$-line is therefore done by calculation. The contribution of ${ }^{152} \mathrm{Eu},{ }^{46} \mathrm{Sc}$ and ${ }^{182} \mathrm{Ta}$ are estimated from other peaks of these radionuclides and subtracted from the sum of the four peaks. For this calculation the same BASIC program is used which is also applied for the calculation of the concentrations of the individual elements from the peaks measured.

The cases of the overlapping lines of ${ }^{239} \mathrm{~Np}$ and ${ }^{182} \mathrm{Ta},{ }^{75} \mathrm{Se}$ and ${ }^{182} \mathrm{Ta}$, ${ }^{203} \mathrm{Hg}$ and ${ }^{239} \mathrm{~Np}$ and ${ }^{75} \mathrm{Se}$ were handled in the same way by calculation as described in the previous paragraph.

If errors due to sampling are not considered, the accuracy of the results obtained is between 10 and $20 \%$ for non-corrected values, whereas the accuracy for values 
W. CALMANO, K. H. LIESER: TRACE ELEMENT DETERMINATION

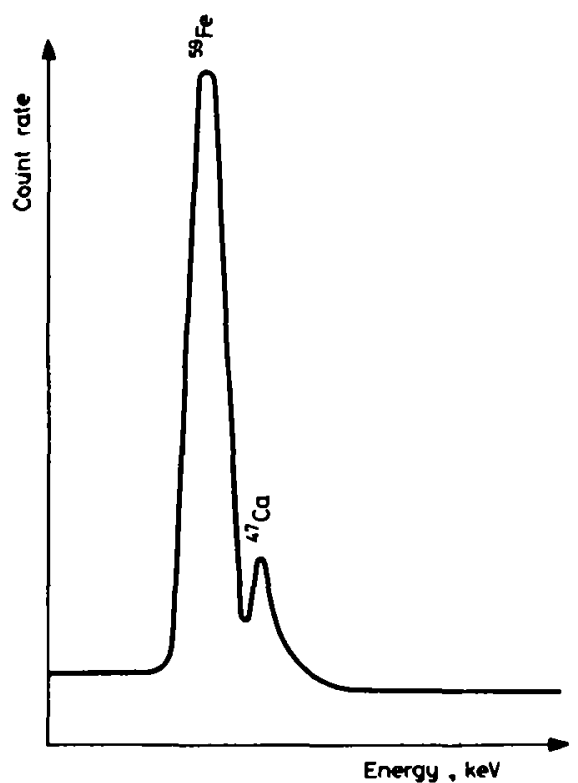

Fig. 2. Overlapping $\gamma$-lines of ${ }^{47} \mathrm{Ca}(1296.8 \mathrm{keV})$ and ${ }^{59} \mathrm{Fe}(1291.6 \mathrm{keV})$



Fig. 3. Overlapping $\gamma$-lines of ${ }^{65} \mathrm{Zn}(1115.5 \mathrm{keV}),{ }^{125} \mathrm{Eu}(1112.1 \mathrm{keV}),{ }^{46} \mathrm{Sc}(1120.5 \mathrm{keV})$ and ${ }^{182} \mathrm{Ta}(1121.2 \mathrm{keV})$ 
which were obtained by correction or subtraction as outlined in this section may be $>20 \%$.

The accuracy of the values was checked by participation in several series of ring analysis. In this way some systematic errors could be eliminated, caused either by overlapping $\gamma$-lines or by use of incorrect constants in the monostandard calibration. With some exceptions $(\mathrm{Ba}, \mathrm{Rb}, \mathrm{Sb}, \mathrm{Se}, \mathrm{U})$ the deviations of the values obtained from the mean values of the ring analysis were $<20 \%$ (Table 3 ). Deviations of this order are well acceptable for water analysis, in particular, for determination of trace elements in suspended matter and sediments.

We thank the "Bundesministerium für Forschung und Technologie" for financial support.

\section{References}

1. K. H. LIESER, W. CALMANO, E. HEUSS, V. NEITZERT, J. Radioanal. Chem., 37 (1977) 717.

2. H. A. VAN DER SLOOT, Dissertation' Petten, 1976.

3. F. ACKERMANN, H. BERMANN, U. SCHLEICHERT, Fresen. Z. Anal. Chem., 296 (1979) 270.

4. F. ACKERMANN, Deut. Gewässerk. Mitt., 21 (1977) 53. 